\title{
Práticas pedagógicas inovadoras: as lutas como conteúdo da educação física no ensino médio
}

\author{
Innovative pedagogical practices: the fights as a content of physical education \\ in middle school
}

DOI: $\underline{\text { http://dx.doi.org/10.36453/2318-5104.2018.v16.n1.p89 }}$

\author{
Carmem Elisa Henn BrandI ${ }^{1}$, Cristiane Boelhouwer ${ }^{2}$, Kymberli Nadine Guios ${ }^{2}$ \\ ${ }^{1}$ Universidade Estadual do Oeste do Paraná (UNIOESTE) \\ ${ }^{2}$ Secretaria Estadual de Educação do Paraná (SEED-PR)
}

\begin{abstract}
RESUMO
Partindo do pressuposto de que as lutas são pouco desenvolvidas nas aulas de educação física, embora façam parte da cultura corporal, portanto dos conteúdos que devem ser ensinados na escola, esta pesquisa teve por objetivo aplicar e avaliar uma proposta pedagógica desse conteúdo, pautada na pedagogia histórico-crítica, comparando o conhecimento inicial e final dos alunos. A pesquisa caracterizou-se como descritiva qualitativa. Participaram da pesquisa uma turma de ensino médio e uma professora de educação física de uma escola estadual do Paraná. Os dados foram coletados por meio de um questionário e através de um diário de campo. O procedimento constou de grupos de estudo, elaboração de material didático, intervenção pedagógica e coleta de dados. Os resultados demonstraram que embora os alunos conheçam diversos tipos de lutas, o conceito é limitado e muitas vezes equivocado, especialmente relacionando-o à violência. Sobre a prática pedagógica, ao comparar o conhecimento prévio com o conhecimento demonstrado após as aulas realizadas, tendo como referência os objetivos propostos, pode-se verificar uma evolução tanto na dimensão conceitual como nas dimensões atitudinal e procedimental. Concluiu-se que a partir de práticas pedagógicas inovadoras e sistematizadas há grande possibilidade de introduzir o conteúdo lutas nas aulas de educação física.
\end{abstract}

PALAVRAS-CHAVE: Educação Física Escolar; Prática Pedagógica; Lutas.

\section{ABSTRACT}

Based on the assumption that the Fights are poorly developed in physical education classes, although they are part of the body culture, and so the contents that must be taught in the school, this research aimed to evaluate a pedagogical proposal of this content, based on pedagogy history- critical, comparing students' initial and final knowledge. The research was characterized as qualitative descriptive. A high school class and a physical education teacher from a State School of Paraná participated in the research. The data was collected through a questionnaire and through a field diary. The procedure consisted of study groups, elaboration of didactic material, pedagogical intervention and data collection. The results showed that while students are aware of different types of fights, the concept is limited and often misleading, especially relating it to violence. On the pedagogical practice, when comparing the previous knowledge with the knowledge demonstrated after the classes carried out, having as reference the proposed objectives, one can verify an evolution in both the conceptual dimension and in the attitudinal and procedural dimensions. It was concluded that from innovative and systematized pedagogical practices there is great possibility of introducing the content fights in the classes of Physical Education.

KEYWORDS: School Physical Education; Pedagogical Practice; Fights. 


\section{INTRODUÇÃO}

A prática pedagógica de professores de educação física das escolas públicas da região é um tema que tem orientado nossas pesquisas na última década. A preocupação se dá, por um lado, em função das mudanças "anunciadas" nas bibliografias publicadas desde a década de 1980 e 1990, e por outro, os resultados de pesquisas sobre as práticas pedagógicas no cotidiano escolar que apontam as dificuldades dos professores de legitimá-las. Soma-se às nossas preocupações a efetivação da legislação e dos documentos oficiais que orientam os currículos e projetos pedagógicos das escolas.

Kravchychyn et al. (2011) ressaltam que mesmo com a legalidade da disciplina no contexto escolar com a promulgação da LDB há quase duas décadas, o seu status não foi legitimado na prática, o que acarreta na falta de identidade e na aplicabilidade da proposta pedagógica da Educação Física no cotidiano da escola.

A história da Educação Física tem mostrado avanços e retrocessos no que diz respeito às práticas pedagógicas identificadas no interior das escolas. Como já citado, muitas das atuais propostas foram elaboradas nas décadas de 1980 e 1990 do século XX, com algumas adaptações realizadas na primeira década do século XXI. No entanto, as pesquisas têm demonstrado que o fato de haver mudanças na legislação e nas propostas pedagógicas não garantiu a materialização das mesmas.

Silva e Bracht (2012) ao tratarem das mudanças ocorridas na educação física escolar, observaram que a "educação física brasileira tem tido muita dificuldade de traduzir seus avanços epistemológicos e teóricos para o campo da intervenção pedagógica, em particular no âmbito escolar" (p. 81).

Neste contexto, e tendo como referência os documentos oficiais que orientam as aulas de educação física na escola, como por exemplo, os Parâmetros Curriculares Nacionais (PCNs) (1998), as Diretrizes Curriculares Estaduais da Educação Básica (DCEs) do Paraná (2008), e atualmente o Base Nacional Curricular Comum (BNCC, 2017), apesar de preverem como conteúdos os jogos, os esportes, as ginásticas, as danças e as lutas, várias pesquisas apontam os esportes como conteúdo hegemônico. Neste sentido, os demais conteúdos, ficam em segundo plano ou ausentes das aulas. Este estudo abordará o conteúdo lutas, uma vez que esse conteúdo é um dos menos trabalhado nas aulas de educação física.

Em sua pesquisa sobre os conteúdos desenvolvidos nas aulas de educação física das escolas estaduais do Paraná, Brandl e Silva (2017) concluíram que $100 \%$ dos participantes aplicam os esportes coletivos e $52,4 \%$ os esportes individuais em suas aulas. Os jogos e brincadeiras, fazem parte das aulas de $95,2 \%$ dos professores, a ginástica $90,5 \%$, danças $88,1 \%$ e lutas $54,8 \%$, entre elas, a capoeira é a luta mais trabalhada pelos professores e em sua maioria, desenvolvem o conteúdo somente na dimensão teórica, através de vídeos, figuras e textos.

Mazini Filho et al. (2014) encontraram um resultado semelhante em sua pesquisa. Dos professores investigados, $56 \%$ afirmaram ministrar lutas dentro das aulas de educação física, enquanto $44 \%$ responderam que não desenvolvem este conteúdo em suas atividades na escola. Ambas as pesquisas apontaram a falta de conhecimento do professor e a falta de espaço físico e material como justificativas para o não desenvolvimento do conteúdo em suas aulas.

Carreiro (2005) reafirma a ideia da ausência das lutas na escola. Para este autor entre os conteúdos que podem ser apresentados na educação física escolar, as lutas são um dos que encontram maior resistência por parte dos professores, com argumentos como: falta de espaço, falta de material, falta de vestimentas adequadas e associação intrínseca às questões de violência.

Conforme Rufino e Darido (2011), as lutas são atividades onde ocorrem disputas, sendo que um indivíduo deve ganhar do outro, utilizando técnicas e táticas de desequilíbrio, dominação, imobilização ou exclusão de um determinado espaço. Para isto utilizam-se técnicas e táticas de ataque e defesa. Para esses autores a principal restrição do ensino das lutas nas aulas de educação física escolar diz respeito à formação deficiente, sendo considerada precária no que corresponde ao ensino dessa prática corporal na escola.

Os mesmos autores, ao citarem Del Vecchio e Franchini, salientam que o domínio das técnicas específicas de uma determinada modalidade de luta leva entre cinco e dez anos, aproximadamente. Por outro lado, no âmbito universitário, a disciplina de lutas apresenta-se usualmente em apenas um ou dois semestres. Apesar de acreditarem que "seria mais importante que o graduando aprendesse a utilizar a luta/arte marcial como estratégia para atingir o objetivo de um programa de educação física em vez de executar técnicas específicas 
de um único estilo durante sua permanência no ensino superior" (DEL VECCHIO; FRANCHINI apud RUFINO; DARIDO, 2015, p. 509).

O presente estudo é parte de uma pesquisa-ação que foi desenvolvida em parceria entre uma universidade pública e professores da rede estadual do ensino básico com a finalidade de contribuir na formação continuada de professores, especialmente buscando a resolução de problemas e a inovação da prática pedagógica em educação física. Entre os problemas apresentados pelos professores participantes, destacou-se a dificuldade de desenvolver o conteúdo lutas em suas aulas.

Levando em consideração esse diagnóstico inicial e as dificuldades apresentadas pelos autores citados, esta pesquisa teve por objetivo aplicar e avaliar uma proposta pedagógica do conteúdo lutas, pautada na pedagogia histórico-crítica, comparando o conhecimento inicial e final dos alunos.

\section{MÉTODOS}

Esta pesquisa se caracteriza como descritiva. Para GIL (1991, p. 46), a pesquisa descritiva "tem como objetivo primordial a descrição das características de determinada população ou fenômeno [...]", justificando ainda que este tipo de pesquisa é muito utilizado por pesquisadores que se preocupam com a atuação prática. Roesch (2005) explica que a pesquisa descritiva qualitativa possibilita estudar os fenômenos dentro de um contexto, sendo esta apropriada para a avaliação formativa, bem como para a análise dos resultados na construção de uma intervenção.

Participaram da pesquisa uma turma de ensino médio com 19 alunos e uma professora de educação física de uma escola estadual do paraná.

O procedimento de coleta dos dados passou por diversas fases: convite aos professores, entrevista inicial, grupos de estudo, elaboração de material didático, intervenção pedagógica, coleta de dados por meio de questionário aos alunos e de um diário de campo com relato das aulas, reflexão em grupo e ajustes do processo pedagógico.

O questionário constou de seis questões abertas, elaborado pelo grupo de estudo e testado com alunos da mesma faixa etária em outra escola e teve por objetivo avaliar o conhecimento prévio dos alunos sobre o conteúdo lutas, abordando conceito, benefícios e danos, tipos de lutas que conhecem, meios que obtiveram o conhecimento, sobre a prática e o interesse em praticar.

Outro instrumento utilizado foi um diário de campo, em que foram feitos os registros de todas as atividades desenvolvidas ao longo de 16 aulas. O diário de campo que foi preenchido pelo professor logo após ministrar as aulas e debatido nos encontros semanais de estudo, permitiu analisar o resultado da prática pedagógica do professor de forma dialógica e não unilateral. A importância do diálogo, entre outras justificativas, se dá pela necessidade de ampliar o campo de visão do contexto onde está inserido o fenômeno pesquisado, além da possibilidade de corrigir/adaptar as dificuldades, durante o processo.

A análise de dados teve caráter qualitativo, extraindo das respostas dos alunos, unidades de significado, que foram reunidas em categorias, quantificadas e apresentadas pela sua frequência absoluta.

Sobre a prática pedagógica, a análise foi qualitativa, utilizando-se da técnica de redução, a partir das informações do diário de campo, comparando o resultado da prática social inicial com a prática social final, tendo como referência o objetivo de cada aula. A apresentação dos resultados se deu de forma descritiva.

\section{RESULTADOS}

0 conhecimento e vivência prévia dos alunos sobre o conteúdo Lutas

Com o objetivo de verificar o conhecimento prévio dos alunos, primeira etapa da proposta pedagógica adotada, aplicou-se um questionário abordando inicialmente o conceito/significado, os benefícios e os danos das lutas para os alunos, os resultados estão demonstrados no Quadro 1. Na sequência, o Quadro 2 apresenta o resultado das questões sobre as lutas que os alunos conhecem, os meios que conheceram e se já praticaram 
algum tipo de luta. Já no Quadro 3 pode-se verificar as lutas e os locais que os alunos já praticaram e qual gostariam de praticar. $\mathrm{O}$ total de respostas não corresponde ao total de sujeitos uma vez que estes poderiam optar por mais que uma alternativa.

Os resultados do Quadro 1 demonstraram que o conceito prévio de lutas dos alunos está predominantemente relacionado a brigas e a violência. Segundo Nascimento e Almeida (2007) além da falta de experiências dos professores, a formação acadêmica limitada quanto às lutas, o preconceito ao conteúdo relacionando-o diretamente com a violência, é o principal fator que limita o desenvolvimento deste rico conteúdo na prática escolar.

Quadro 1. Conhecimento dos alunos sobre conceito/significado, benefícios e danos das lutas.

\begin{tabular}{|ll|llll|}
\hline Conceito/Significado & $f a$ & Benefícios & $f a$ & Danos & $f$ \\
\hline Briga & 9 & Agilidade & 3 & Machucados & 6 \\
\hline Lutas de UFC & 4 & Defesa & 2 & Lesões graves & 4 \\
\hline WWE & 1 & Dinheiro & 2 & Morte & 1 \\
\hline Agressão física & 2 & Respeito aos outros & 1 & Violência & 1 \\
\hline Lesões & 1 & Competição & 1 & Apanhar & 1 \\
\hline Morte & 2 & Você fica melhor na briga & 1 & Prejudicar alguém & 1 \\
\hline Espancamento & 2 & Para bater nos outros & 4 & Ferimentos no corpo & 1 \\
\hline Sangue & 2 & Ajuda a manter a saúde praticando & 1 & Hematoma & 1 \\
\hline Judô & 1 & Não sei & 1 & & \\
\hline Karatê & 1 & Salvar vida & 1 & & \\
\hline Quebra pau & 1 & Título mundial & 1 & & \\
\hline Bater e defender-se & 3 & Aprende & 1 & & \\
\hline Boxe & 2 & Fama & 3 & & \\
\hline MMA & 1 & Melhoramento físico & & & \\
\hline Agressividade & 1 & & 30 & & \\
\hline Vale tudo & 1 & & & & \\
\hline Total & 34 & & & & \\
\hline
\end{tabular}

Segundo Mazini Filho et al. (2014), é necessário que os professores de educação física escolar saibam e ensinem a diferença entre lutas e brigas para seus alunos, independente da modalidade. Para os autores, enquanto a primeira trata-se de uma prática esportiva ou alternativa de atividade física com regras determinadas, a segunda é vista como uma forma de provocar confusões, desrespeito ao próximo, gerando violência excessiva.

Sobre os benefícios, apesar de predominar nas respostas a defesa pessoal, os alunos também se reportaram aos benefícios físico/motores e sócio/emocionais. A maioria dos alunos acredita que as lutas causam danos físicos como machucados e lesões.

Para Mazini Filho et al. (2014), a prática das Lutas apresenta benefícios nas diferentes dimensões, os autores citam melhoras de valores como: desenvolvimento do cidadão, expressões corporais, movimentos, capacidades físicas, moral e respeito entre os participantes, promoção da saúde entre outros. Os autores reforçam que por esta razão seu desenvolvimento se encaixa dentro dos conteúdos da educação física escolar.

Em relação as modalidades que conhecem, o judô aparece em primeiro lugar, seguido de UFC, MMA, Jiujítsu, Muay Thai, Boxe. Afirmaram ter conhecido essas Lutas principalmente pela televisão o que reforça a ideia de Correia (apud Rodrigues et al., 2017) quando escreve que a visibilidade atual das lutas tem alcançado níveis jamais vistos na história, com expansão das tecnologias e do processo de globalização. Pequena parte dos alunos já praticou algum tipo de luta em um projeto oferecido pelo município. A maioria dos alunos gostaria de praticar alguma das modalidades e o judô foi a mais citada. 
Apesar de apresentarem um conceito/significado predominantemente negativo sobre as lutas, listaram maior número de benefícios do que danos, sendo o maior benefício a defesa pessoal. Outro aspecto a ser observado, o grande número de modalidades citadas por alguns dos alunos, demonstrando certo conhecimento sobre o tema. Também há de se destacar, no Quadro 3, o número de alunos (08) que já praticou alguma modalidade, alguns inclusive mais de um tipo de luta, oportunizada especialmente por um projeto do município e pela escola.

Quando perguntados sobre a possibilidade de praticar lutas na escola, grande parcela dos alunos respondeu que gostaria e que há possibilidades, no entanto, ao citar as lutas que gostariam de praticar, um número considerável de alunos (07) respondeu nenhuma.

Quadro 2. Conhecimento dos alunos sobre as modalidades, meios que conheceu e se já praticou lutas.

\begin{tabular}{|lc|lc|lc|}
\hline $\begin{array}{l}\text { Modalidades } \\
\text { que conhece }\end{array}$ & fa & $\begin{array}{l}\text { Meios de } \\
\text { conhecimento }\end{array}$ & fa & Se já praticou & fa \\
\hline Judô & 18 & TV & 18 & Sim & 8 \\
\hline Jui Jitsu & 5 & Amigos & 5 & Não & 11 \\
\hline UFC & 9 & Escola & 1 & & \\
\hline Capoeira & 4 & Internet & 3 & & \\
\hline Kung-Fu & 2 & Academia & 2 & & \\
\hline MMA & 6 & & & & \\
\hline Muay Tay & 4 & & & & \\
\hline Boxe & 3 & & & & \\
\hline Karatê & 4 & & & & \\
\hline WWE & 1 & & & & \\
\hline Luta livre & 1 & & & & \\
\hline Total & 57 & & 29 & & \\
\hline
\end{tabular}

Quadro 3. Tipos de lutas e local que os alunos praticaram e qual gostaria de praticar.

\begin{tabular}{|lc|lc|lc|}
\hline Lutas que praticou & $f a$ & Local onde praticou & $f a$ & $\begin{array}{l}\text { Qual luta gostaria } \\
\text { de praticar }\end{array}$ & $f a$ \\
\hline Judô & 6 & Projeto Pia & 3 & Boxe & 1 \\
\hline Jui- Jitsu & 2 & Em casa & 1 & Capoeira & 3 \\
\hline Kung-Fu & 1 & Academia de judô & 1 & Judô & 4 \\
\hline Luta livre & 1 & Escola & 3 & Jui-jitsu & 1 \\
\hline Capoeira & 1 & & & Kung-fu & 1 \\
\hline & & & Nenhuma & 7 \\
\hline & & & Não souberam & 02 \\
\hline Total & 11 & & & & 19 \\
\hline
\end{tabular}

\section{Resultado da prática pedagógica do conteúdo lutas}

Tendo em vista que o encaminhamento metodológico para as aulas de educação física na educação básica, determinado nas Diretrizes Curriculares do Paraná é a pedagogia histórico-crítica, este projeto também seguiu estas orientações. A pedagogia histórico-crítica, segundo Ricci et al. (2008), tem origem nos estudos de 
Demerval Saviani. Esta proposta, segundo os autores, procurou melhor delimitar a pedagogia dialética entre as pedagogias críticas.

Em relação à Educação Escolar, Saviani (1992) escreve que a pedagogia histórico-crítica se empenha na defesa da especificidade da Escola.

\begin{abstract}
"A escola tem a função específica, educativa, propriamente pedagógica, ligada a questão do conhecimento, é preciso, pois, resgatar a importância da escola e reorganizar o trabalho educativo, levando em conta o problema do saber sistematizado, a partir do qual se define a especificidade da Educação Escolar" (p. 101).
\end{abstract}

Para Gasparin (2009), os conteúdos tem a finalidade social de ser integrados e aplicados no dia a dia dos alunos. Para o autor, isso implica em trabalhar os conteúdos de forma contextualizada em todas as áreas do conhecimento. Essa metodologia de ensino-aprendizagem, segundo o autor, apresenta três novos desafios aos professores e alunos: uma nova maneira de planejar as atividades; um novo processo de estudo por parte do professor; novo método de trabalho. A didática proposta por Gasparin (2009) para pedagogia histórico-crítica é articulada em cinco momentos: "Prática social inicial do conteúdo", "Problematização", "Instrumentalização", "Catarse", e "Prática Social final do conteúdo".

Sobre o encaminhamento metodológico da educação física, pautado na pedagogia histórico-crítica, nas Diretrizes Curriculares do Paraná (PARANÁ, 2008) é citado que é preciso, inicialmente, levar em conta aquilo que o aluno traz como referência acerca do conteúdo proposto. Após o conhecimento daquilo que os alunos conhecem sobre o tema, o professor instiga-os a pensar sobre o tema remetendo-o ao cotidiano, criando um ambiente de dúvidas sobre os conhecimentos prévios. Posteriormente, o professor apresentará aos alunos o conteúdo sistematizado, tanto na dimensão teórica como também a vivência das manifestações da cultura corporal, dando condições aos alunos de refletirem e recriarem as propostas. Finalizando aquele tema, desenvolvido em uma aula ou um conjunto de aulas, o professor propõe, junto com os alunos um diálogo que permitirá a avaliação do processo de ensino/aprendizagem.

O projeto de intervenção foi desenvolvido em dezesseis aulas de educação física, sendo duas aulas geminadas uma vez por semana e seguiu os passos desta proposta. A análise das aulas, realizada a partir do diário de campo preenchido pelo professor e analisado pelo grupo de estudo, seguiu a mesma trajetória. No entanto, no espaço deste artigo foi não foi considerado todo o processo, mas a relação entre o objetivo proposto e as avaliações do conhecimento inicial e final do aluno.

Ao comparar os resultados da avaliação inicial e final referente ao objetivo proposto para as aulas 1 e 2 , que foi diagnosticar o conhecimento dos alunos sobre o conteúdo lutas e vivenciar brincadeiras de lutas, podese identificar que apesar dos alunos inicialmente associarem a luta com violência, ao vivenciar as atividades, que tiveram um caráter lúdico, sem preocupação com modalidades ou técnicas específicas, participaram de forma ativa e divertida, mas especialmente sem praticar atos violentos. Pode-se atribuir este comportamento a forma como o professor conduziu sua aula e a escolha das atividades, proporcionando uma visão diferente ao conceito inicial apresentado pelos alunos.

Para Rodrigues et al. (2017) os objetivos e metodologias utilizados para o ensino das lutas no ambiente escolar, deve oportunizar uma prática pedagógica diferenciada, que permita novas vivências e experiências para retomada de valores comportamentais, sociais e culturais, beneficiando o desenvolvimento e formação. Também para Cintra et al. (2016, p. 131) "a luta deve ser abordada não apenas por questões técnicas e táticas e sim, como aporte histórico-cultural, com caráter lúdico e seu ensino transformado didaticamente para melhor se adequar ao ensino escolar".

Na sequência das aulas, com o objetivo de diferenciar luta de briga, observou-se no material coletado, que inicialmente ambas estavam associadas à violência e representavam agressão física e defesa pessoal. Após as aulas, em que foram apresentadas imagens de pessoas brigando e de pessoas praticando algum tipo de luta, para alguns dos meninos as figuras de brigas foram comparadas com seus momentos explosivos e de poder e simbolizavam imposição de respeito. Para a maioria das meninas, representavam ignorância de pessoas e atitude agressiva e falta de respeito. Com relação aos tipos de lutas mostrados nas imagens, a grande maioria acertou todos os tipos e começaram a entender que lutas têm regras e não precisam ser violentas. 
Mazini Filho et al. (2014) também consideram necessário que os professores de educação física escolar, saibam ensinar a diferença entre lutas e brigas para seus alunos, tendo em vista que a primeira trata-se de uma prática esportiva ou alternativa de atividade física com regras determinadas e a segunda é vista como uma forma de provocar confusões, desrespeito ao próximo, gerando violência excessiva.

O objetivo da quinta e sexta aula foi de conhecer a filosofia e os diferentes tipos de lutas e vivenciar atividades de ataque e defesa. Em suas colocações iniciais relataram que não tinham conhecimento da finalidade das lutas, dos significados que elas representavam. Em relação a história, relacionaram com defesa pessoal, especialmente à antiguidade e, ao trazer para a própria realidade, com suas histórias de vida, compararam com os momentos de briga.

Após as aulas, alguns meninos ainda apontaram que determinadas lutas (como MMA, WWE e Boxe) geram violência. Já as meninas não opinaram, apenas comentaram que não gostavam de luta por ser muito violento. Sobre as atividades práticas da aula, os alunos gostaram e concluíram que não houve briga e discussão, embora no início tivessem receio de participar. A aula foi recreativa sem exigência de técnica, por este motivo puderem criar as próprias estratégias de ataque e defesa. Todos relataram que não foi necessário usar de violência para se defender, apenas a utilização de estratégias. A conclusão dos alunos desta aula sobre a diferença de briga e de lutas foi de que as últimas, quando associadas as suas filosofias, são muito diferentes, compreendendo que nas lutas precisam respeitar uns aos outros.

A sétima e oitava aula teve como tema a capoeira e inicialmente o objetivo foi de identificar o conhecimento dos alunos, conhecer a história, sua implicação para a cultura corporal e alguns movimentos, como por exemplo, a ginga. Após questionar os alunos percebeu-se que já tinham algum conhecimento do tema, argumentaram que a capoeira era uma luta em que não se atinge o adversário; sua origem, de forma equivocada, era indígena; e que tinha instrumentos, os quais não conheciam. Tanto homens como mulheres, crianças, negros e brancos poderiam praticar. Também citaram que é praticada em forma de dança, de ritual, de luta e golpes.

Como conhecimento adquirido, os alunos, na roda de conversa final, relataram que apesar de todo sofrimento, da escravidão, da exclusão e do racismo, os negros conseguiam aproveitavam alguns momentos para a diversão, demonstrando assim certa compreensão sobre o aspecto histórico da capoeira. Na aula prática, os alunos foram participativos, interagiram nas respostas quando questionados e puderam se divertir vivenciando movimentos de estrela e salto.

Dando sequência a modalidade de capoeira, a nona e décima aula, teve como objetivo conhecer alguns movimentos básicos e vivenciar alguns ritmos e exercícios corporais, além da roda de capoeira. Apesar de inicialmente não se sentirem motivados para a aula, e de demonstrarem certa resistência e desinteresse pelo conteúdo, levando a professora a considerar que a aula não daria certo, após uma intervenção diretiva, houve razoável participação e, de forma geral, não tiveram grandes dificuldades em realizar as atividades.

Nas aulas seguintes, manteve-se o mesmo objetivo, tendo em vista que não foi alcançado nas aulas anteriores. No começo da aula predominou novamente a falta de interesse e reclamações por parte dos alunos, alguns inclusive não realizaram a atividade, outros realizaram os movimentos de maneira mais descontraída. A grande maioria teve dificuldades de realizar os movimentos, mesmo com o auxílio e incentivo da professora e dos colegas.

Sobre a aprendizagem dos movimentos da capoeira, concluiu-se que grande parte não demonstrou avanço em relação ao conhecimento inicial. Entre os motivos pode-se citar a falta de interesse pelo conteúdo, uma vez que queriam praticar outras atividades, e a vergonha de realizar determinados movimentos. Essa falta de interesse gerou indisciplina. A exposição dos alunos para determinados movimentos, inclusive dificuldade em realizá-los, fez com que não houvesse muita aceitação da aula. Quando questionados sobre as dificuldades de se praticar os elementos da capoeira, eles apenas comentaram que não tinham vivenciado essas atividades. A percepção que eles apresentaram sobre este conteúdo, é de que a capoeira na atualidade é vista como uma dança, uma cultura da região nordeste do Brasil, direcionada para quem gosta mais de ritmos e ginga, comentaram que não veem a capoeira como uma briga ou uma luta, mas como uma diversão.

Após a realização das seis aulas do conteúdo, chega-se a conclusão de que o objetivo foi alcançado parcialmente uma vez que não houve motivação para a aprendizagem e, até certo ponto houve rejeição, talvez 
por não fazer parte da cultura regional e por não ter havido compreensão de que este conteúdo faz parte da cultura corporal de movimento, portanto dos conteúdos da educação física escolar. Mello (apud CINTRA et al., 2016, p. 132) escreve que "a capoeira é plural, e nela o lúdico e o combativo interpenetram-se, caracterizando-a como jogo, luta e dança". Neste sentido, os autores consideram uma modalidade rica para ser trabalha em ambiente escolar, oportunizando inclusive de trabalhar com a interdisciplinaridade.

Nas aulas 13 e 14, o conteúdo foi judô e o objetivo identificar o conhecimento dos alunos em relação à modalidade, através de uma aula teórica. Os alunos tinham como conceito, na avaliação inicial da aula, que o judô é um modo de defesa, tem faixas e quimono, é realizado em tatames, tem árbitros e competições, é praticada por duas pessoas com intenção de derrubar, foi criado por alguém que eles não lembravam o nome. Durante a aula tiveram oportunidade de estudar um pouco de história e a filosofia do judô através de pesquisa e elaboração de cartazes despertando interesse pela modalidade, inclusive de praticá-la. Como identificado no questionário aplicado aos alunos no início da pesquisa, parte deles já praticou o judô, o que justifica o conhecimento deles sobre o tema.

Nas últimas aulas (aulas 15 e 16) o objetivo foi de conhecer e vivenciar alguns movimentos básicos de judô. Essa aula foi realizada fora do espaço escolar em um tatame de um projeto do poder público da cidade. Alguns alunos não participaram justificando que tinham vergonha e outros que tinham medo de se machucar. As atividades iniciais foram a prática de quedas, atividade de desequilibrar o colega ajoelhado, demonstração e experimentação de alguns golpes. A grande maioria dos alunos participou das atividades e comentou que foi interessante e divertida a aula. Também relataram que conseguiram compreender melhor a história, a filosofia e o motivo da origem do judô. A realização de técnicas de quedas e golpes reforçou a importância de respeitar as regras e o adversário, além da prática em local e hora adequados.

Rufino e Darido (2015) constataram em sua pesquisa que é possível desenvolver o conteúdo lutas na escola, apesar da deficiência ou inexistência de espaço físico adequado.

\section{CONSIDERAÇÕES FINAIS}

Embora as lutas façam parte dos conhecimentos da cultura Corporal e, portanto, deva ser ensinado nas Escolas, percebeu-se, pela literatura consultada, que esta não é a realidade da maioria das escolas. Essa percepção foi reforçada ao questionar o professor da turma sobre qual o conteúdo menos trabalhado na escola, e o mesmo apontou as lutas, justificando dessa forma a escolha do tema para desenvolver a Pesquisa.

Ao avaliar a proposta pedagógica desse conteúdo, elaborada e acompanhada por um grupo de estudos, aplicada por uma professora do grupo em uma turma de ensino médio, foi necessário, inicialmente identificar o conhecimento prévio, ou a prática social inicial desses alunos em relação às lutas. Concluiu-se que, embora os alunos conhecessem diversos tipos de lutas, informação esta obtida especialmente através da mídia, o conceito é limitado e muitas vezes equivocado, relacionando-a a violência. O maior benefício apontado pelos alunos foi a defesa pessoal, embora também considerassem que as lutas possam trazer danos físicos como machucados e lesões. Entre as modalidades de lutas identificadas pelos alunos a mais citada foi o judô, inclusive tendo alguns já a praticado, e outros, que gostariam de praticar.

Sobre a prática pedagógica, inovadora para esta turma e esta professora, ao comparar o conhecimento prévio dos alunos com o conhecimento demonstrado após as aulas realizadas, tendo como referência os objetivos propostos, pode-se verificar uma evolução tanto na dimensão conceitual como nas dimensões atitudinal e procedimental.

Ao vivenciar brincadeiras de lutas, participaram de forma ativa e divertida, mas especialmente sem praticar atos violentos. Quando solicitados a diferenciar, a partir da demonstração de figuras, lutas de brigas, houve a compreensão de que as primeiras têm regras e não precisam ser violentas, enquanto as brigas se dão em outro contexto e normalmente são formas de demonstrar poder. No entanto, após a aula teórica sobre a filosofia e os diferentes tipos de lutas, alguns meninos ainda apontaram que determinadas modalidades são violentas, como por exemplo, MMA, WWE e Boxe. Apesar dessa constatação, a maioria concluiu que quando as Lutas são associadas as suas filosofias, são muito diferentes, compreendendo que nelas precisam respeitar uns aos outros e suas regras. Essa compreensão foi reforçada ao vivenciarem atividades de ataque e defesa, 
nas quais os alunos gostaram e concluíram que não houve briga e discussão, embora no início tivessem receio de participar. A metodologia de ensino utilizada possibilitou que os alunos criassem as próprias estratégias, sem usar de violência.

Quanto à capoeira, percebeu-se que já tinham algum conhecimento teórico sobre a história e conceito, mas não haviam praticado. Nas atividades práticas recreativas houve boa aceitação e participação, já em relação aos movimentos básicos e a vivência de alguns ritmos, além da roda de capoeira, concluiu-se que grande parte não demonstrou avanço em relação ao conhecimento inicial. Entre os motivos, pode-se citar a falta de interesse pelo conteúdo, a vergonha em se expor ao realizar determinados movimentos, a dificuldade motora ao realizar algumas acrobacias, além do tempo curto da prática e a indisciplina na aula.

A modalidade de judô foi a que os alunos demonstraram maior conhecimento conceitual. Durante as aulas tiveram oportunidade de estudar a história e a filosofia do judô e de praticá-lo. Embora parte dos alunos já tivesse praticado a modalidade, alguns não participaram justificando que tinham vergonha e outros que tinham medo de se machucar. Aqueles que participaram das aulas práticas consideraram-nas interessantes e divertidas. Também relataram que conseguiram compreender melhor a história, a filosofia e o motivo da origem do judô. A realização de técnicas de quedas e golpes reforçou a importância de respeitar as regras e o adversário, além de praticar em local adequado.

Após a realização da pesquisa, conclui-se que a partir de práticas pedagógicas inovadoras e sistematizadas, há grande possibilidade de introduzir o conteúdo lutas nas aulas de educação física, a exemplo dessa pesquisa. Reforça-se a importância do diagnóstico inicial, seguido de uma intervenção sistematizada através da prática pedagógica participativa, acompanhada de reflexões constantes e coletivas do processo, proporcionadas, neste caso, pelo grupo de estudo, além da avaliação da prática social final, ou seja, do conhecimento adquirido pelo aluno.

Espera-se que este estudo possa contribuir para a introdução do conteúdo lutas na prática pedagógica de professores de educação física.

\section{REFERÊNCIAS}

BETTI, M. Educação física escolar: ensino e pesquisa-ação. Injuí: Unijuí, 2009.

BRANDL, C. E. H.; SILVA JÚNIOR, A. P. Um estudo sobre a aplicação das Diretrizes Curriculares Estaduais do Paraná na prática pedagógica de professores de Educação Física. In: 8o Congresso Norte Paranaense de Educação Física Escolar. Anais... 8o Congresso Norte Paranaense de Educação Física Escolar Londrina: UEL, 2017.

BRASIL. Base Nacional Curricular Comum. BNCC. Brasília: MEC/SEF, 2017. Disponível em: <http:// basenacionalcomum.mec.gov.br/wp-content/uploads/2017/12/BNCC_EnsinoMedio embaixa_site. pdf> Acessado em: 12 de dezembro de 2017.

BRASIL. Ministério da Educação e do Desporto, Secretaria de Educação Básica. Parâmetros Curriculares Nacionais - Educação Física. Brasília: MEC/SEF, 1997.

CARREIRO, E. A. Lutas. In: DARIDO, S. C.; RANGEL, I. C. A. Educação física na escola: Implicações para a prática pedagógica. Rio de Janeiro: Guanabara Koogan, 2005.

CINTRA, M. M.; LEMOS, M. P.; CAMPOS, L. A. S.; SIMÕES, R. O ensino das lutas na educação física escolar: o estado da arte. Coleção Pesquisa em Educação Física, Várzea Paulista, v. 15, n. 1, p. 12734, 2016.

GASPARIN, J. L. Uma didática para a pedagogia histórico-crítica. 5. ed. Campinas: Autores Associados, 2009.

GIL, A. C. Como elaborar projetos de pesquisa. São Paulo: Atlas, 1991.

KRAVCHYCHYN, C.; CARDOSO, S. M. V.; MORETTI, L. H. T.; OLIVEIRA, A. A. B. Educação física escolar brasileira: caminhos percorridos e "novas/velhas" perspectivas. Revista Teoria e Prática da Educação, Maringá, v. 14, n. 1, p. 107-18, 2011. 
MAZINI FILHO, M. L.; SIMÕES, M. R.; VENTURINI, O. G. R.; SAVÓIA, R. P.; MATTOS, D. J.; AIDAR, F. J.; COSTA, S. P. O ensino de lutas nas aulas de educação física escolar. Cinergis, Santa Cruz do Sul, v. 15, n. 15, p. 176-81, 2014.

NASCIMENTO, P. R. B.; ALMEIDA, L. A tematização das lutas na educação física escolar: restrições e possibilidades. Movimento, Porto Alegre, v. 13, n. 3, p. 91-110, 2007.

PARANÁ. Diretrizes Curriculares Estaduais da Educação Básica do Paraná. Curitiba: Secretaria de Estado de Educação, 2008. Disponível em: <http://www.educadores.diaadia.pr.gov.br/arquivos/File/ diretrizes/dce edf.pdf> Acessado em: 8 de dezembro de 2017.

RICCI, M. C. P. A ginástica geral na educação física escolar e a pedagogia histórico-crítica. Lecturas: Educación Física y Deportes, Revista Digital, Buenos Aires, v. 12. n. 116, 2008. Disponível em: <http:// www.efdeportes.com/efd116/a-ginastica-geral-na-educacao-fisica-escolar.htm> Acessado em: 8 de dezembro de 2017.

RODRIGUES, A. I. C.; BAIÃO JUNIOR, A. A.; ANTUNES, M. M.; ALMEIDA, J. J. G. Percepção dos dirigentes das escolas do município de Jaguariúna sobre as lutas. Journal of Physical Education, Maringá, v. 28, e2809, 2017.

ROESCH, S. M. A. Projetos de estágios e de pesquisa em administração: guia para estágios, trabalhos de conclusão, dissertações e estudo de caso. São Paulo: Atlas, 2005.

RUFINO, L. G. B; DARIDO, S. A separação dos conteúdos das "lutas" dos "esportes” na educação física escolar: necessidade ou tradição? Pensar a Prática, Goiânia, v. 14, n. 3, p. 117, 2011.

RUFINO, L. G. B; DARIDO, S. O ensino das lutas nas aulas de educação física: análise da prática pedagógica à luz de especialistas. Revista de Educação Física/UEM, Maringá, v. 26, n. 4, p. 505-18, 2015.

Autor correspondente: Carmem Elisa Henn Brandl

E-mail: c.brandl@hotmail.com

Recebido: 6 de abril de 2018.

Aceito: 14 de maio de 2018. 